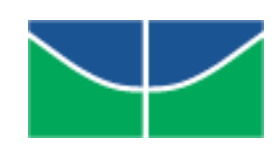

Universidade de Brasília

Faculdade de Economia, Administração e Contabilidade

Departamento de Administração

Curso de Graduação em Administração a distância

ELENIRA DOS SANTOS MESQUITA

\title{
A RETAGUARDA BANCÁRIA E A APLICABILIDADE OPERACIONAL DA ANÁLISE E LIBERAÇÃO DOS EMPRÉSTIMOS DO PROGRAMA MINHA CASA, MINHA VIDA
}

Brasília - DF 


\section{ELENIRA DOS SANTOS MESQUITA}

\section{A RETAGUARDA BANCÁRIA E A APLICABILIDADE OPERACIONAL DA ANÁLISE E LIBERAÇÃO DOS EMPRÉSTIMOS DO PROGRAMA MINHA CASA, MINHA VIDA}

Monografia apresentada a Universidade de Brasília (UnB) como requisito parcial para obtenção do grau de Bacharel em Administração.

Professor Orientador: Dr. José Matias-Pereira

Professor Co-Orientador: Especialista Marcos Ozório de Almeida

Brasília - DF 
Mesquita, Elenira dos Santos.

A Retaguarda Bancária e a Aplicabilidade Operacional da Análise e Liberação dos Empréstimos do Programa Minha Casa, Minha Vida/ Elenira dos Santos Mesquita. - Brasília, 2010.

$97 \mathrm{f}$. : il.

Monografia (bacharelado) - Universidade de Brasília, Departamento de Administração - EaD, 2010.

Orientador: Prof .Dr. José Matias-Pereira, Departamento de Administração.

1. O Comitê de Basiléia. 2. Programa Minha Casa, Minha Vida. I. Título. 


\section{ELENIRA DOS SANTOS MESQUITA}

\section{A RETAGUARDA BANCÁRIA E A APLICABILIDADE OPERACIONAL DA ANÁLISE E LIBERAÇÃO DOS EMPRÉSTIMOS DO PROGRAMA MINHA CASA, MINHA VIDA}

A Comissão Examinadora, abaixo identificada, aprova o Trabalho de Conclusão do Curso de Administração da Universidade de Brasília do (a) aluno (a)

Elenira dos Santos Mesquita

Dr. José Matias-Pereira

Professor-Orientador

Especialista Marcos Ozório de Almeida Professor Co-Orientador
Especialista Josias Rodrigues Alves

Professor-Examinador 
Trabalho dedicado ao meu pai Raimundo Pereira de Mesquita. Um homem que coloca Deus acima de tudo, em todos os momentos de sua vida. Valoriza a busca do conhecimento, incentivando o desenvolvimento acadêmico e profissional de seus familiares. E ressalta sempre a importância do fortalecimento dos sentimentos nobres em nossa conduta diária. 


\section{AGRADECIMENTOS}

Agradeço a Deus e à espiritualidade pela coragem, determinação e inspiração. Agradeço à minha família, esposo e filhas pela infinita paciência que tiveram comigo, e pelo incentivo de todas as horas. Agradeço aos professores, em especial aos dessa disciplina, pelo apoio, pela orientação e conhecimento repassados. E, finalmente, também agradeço à Universidade de Brasília pela oportunidade dessa graduação em Administração. 
"Não temos escolhas: temos de chamar as pessoas para o processo de repensar; reprojetar e reestruturar a organização...Se elas estiverem envolvidas, vão criar um futuro do qual elas mesmas fazem parte."

(Fritjof Capra) 


\section{RESUMO}

O presente estudo teve como objetivo analisar os processos administrativos e operacionais que envolvem a liberação e análise do empréstimo Minha Casa, Minha Vida, dentro da retaguarda de um grande banco público brasileiro. Discorre-se sobre a evolução do sistema bancário, em especial dos bancos brasileiros, até chegar à formalização do Acordo da Basiléia. Avalia-se as atividades desenvolvidas, objetivando identificar possíveis "gargalos" nas rotinas e sugerir-se a otimização dos processos utilizados. Para tal, uma pesquisa quantitativa interna foi realizada, abrangendo empregados de agências bancárias e empregados da retaguarda bancária. Verificou-se que 0 desenvolvimento completo da atividade esbarra, principalmente, na falta de conhecimento sobre o produto, visto que alguns poucos empregados detêm o conhecimento. Por tratar-se de uma rotina nova, diversos ajustes operacionais serão necessários. Conclui-se com a sugestão de aprimoramento de tarefas, disseminação do conhecimento e manutenção desta atividade no ambiente de retaguarda bancária.

Palavras-chave: Controle . Conformidade. Execução. Otimização. Evolução. Bancos. Acordo. Supervisão Bancária. 


\section{LISTA DE ABREVIATURAS E SIGLAS}

PMCMV - Programa Minha Casa, Minha Vida

CAIXA - Caixa Econômica Federal

G 10 - Grupo dos dez países mais ricos do mundo

PIS - Programa de Integração Social

FGTS - Fundo de Garantia por Tempo de Serviço

PROER - Programa de Estímulo à Reestruturação do Sistema Bancário Brasileiro

BIS - Bank for International Settlements (Banco de Compensações Internacionais)

PNHU - Programa Nacional de Habitação Urbana

FGHab - Fundo Garantidor da Habitação Popular

PNHR - O Programa Nacional de Habitação Rural

FAR - Fundo de Arrendamento Residencial

FDS - Fundo de Desenvolvimento Social 


\section{SUMÁRIO}

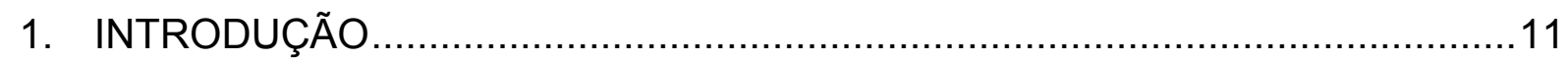

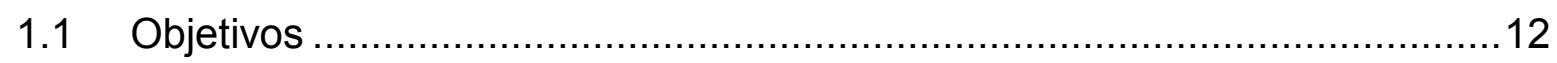

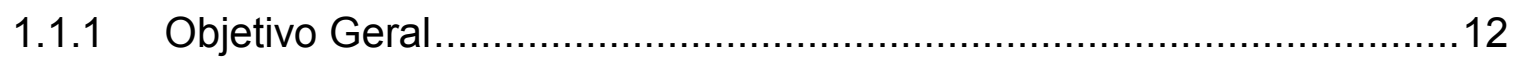

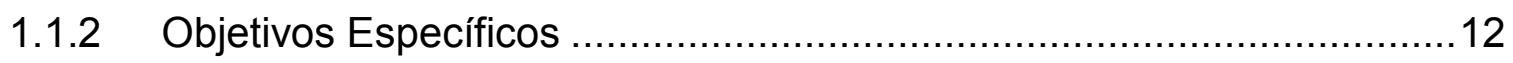

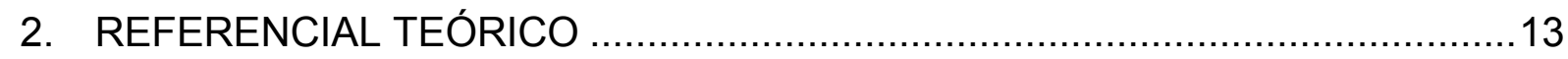

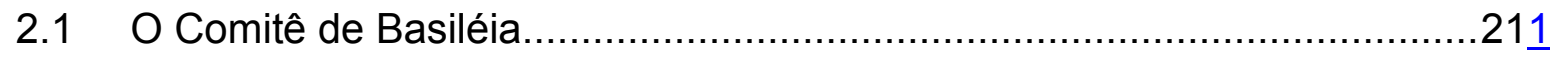

2.1.1 O Acordo da Basiléia...................................................................... 21

2.3 Programa Minha Casa, Minha Vida ......................................... $25 \underline{5}$

3. MÉTODOS E TÉCNICAS DE PESQUISA ..............................................28

3.1 População e Amostra ...................................................................28

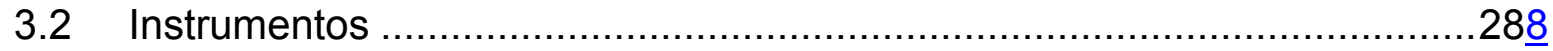

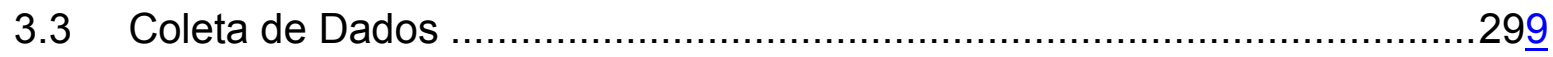

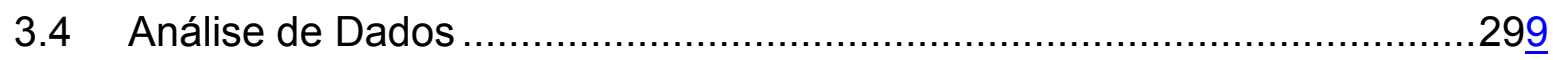

4. REGISTRO DOS RESULTADOS E DISCUSSÃO ..................................... 30

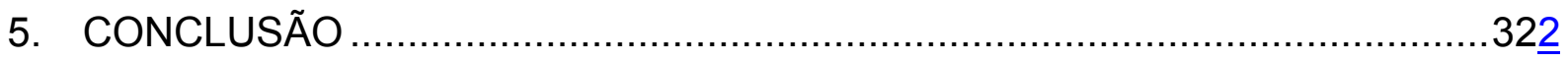

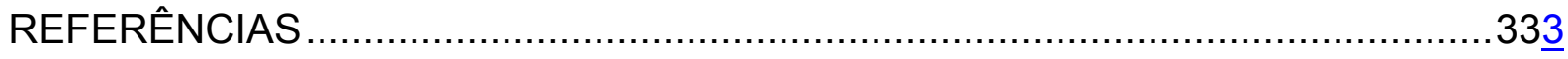

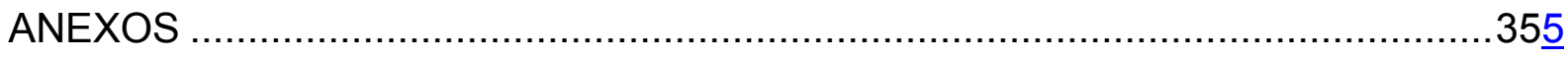

Anexo I - Questionário de Pesquisa .................................................

Anexo II - Princípios do Acordo da Basiléia................................................. $38 \underline{8}$ 


\section{INTRODUÇÃO}

A regulação prudencial nos bancos públicos brasileiros faz-se cada vez mais importante, tendo em vista os problemas econômicos que colocaram em dúvida a solidez financeira de determinadas instituições no Brasil e no mundo.

Este presente estudo sobre a retaguarda bancária e a aplicabilidade operacional da análise e liberação dos empréstimos do programa Minha Casa, Minha Vida, tem por objetivo comparar algumas vertentes teóricas que existem em torno do papel das áreas de controle e conformidade das instituições financeiras.

O trabalho abordará a variáveis envolvidas na concessão de um empréstimo do Programa Minha Casa, Minha Vida, sendo realizado dentro das unidades de retaguarda de um grande banco brasileiro.

Esta pesquisa é direcionada a todos os empregados de bancos públicos, pois definidas as nuances, será mais fácil para cada um assimilar seu papel e, até mesmo, colaborar com os colegas de outras áreas.

Tal pesquisa justifica-se pelo fato de que somos conhecedores da importância da existência de um controle das operações financeiras, mas sabese também que os negócios requerem rapidez e dinamismo na sua captação e concretização, devido a concorrência no mercado financeiro.

Procura-se, assim, esclarecer a importância da existência das unidades de retaguarda dentro das instituições financeiras, e suas vantagens e desvantagens.

O interesse do pesquisador em propor esta investigação está embasado no fato dele mesmo ser empregado do banco em questão, e deter possibilidades concretas de realizar os estudos necessários "in loco".

Atualmente, no mercado econômico e financeiro, percebe-se uma grande necessidade de adequação à orientações, normas e controles, objetivando minimizar riscos e manter a estabilidade das instituições.

Visando tal prática, procura-se avaliar os processos pertinentes à retaguarda bancária, e em especial ao programa governamental Minha Casa, Minha Vida. Para tanto, pesquisa-se sobre as vantagens e desvantagens da 
inserção do referido programa numa retaguarda e não em uma agência bancária.

\subsection{Objetivos}

\subsubsection{Objetivo Geral}

Identificar a percepção dos empregados de um grande banco brasileiro sobre a implantação da análise do empréstimo Minha Casa, Minha Vida, dentro da retaguarda, bem como verificar se existe de ganhos operacionais na realização de análise e concessão do empréstimo Minha Casa, Minha Vida, na Retaguarda Bancária.

\subsubsection{Objetivos Específicos}

1)Identificar os processos e atividades desenvolvidas na concessão de empréstimos habitacionais;

2)Identificar e analisar as ferramentas utilizadas;

3)Identificar vantagens e desvantagens do serviço oferecido. 


\section{REFERENCIAL TEÓRICO}

Este capítulo tem por objetivo apresentar uma base teórica sobre o assunto abordado, porém não tem a pretensão de apresentar todos os estudos e teorias já publicados em torno do tema. Abordaremos itens que de alguma forma se destaquem e sejam imprescindíveis para o completo entendimento das questões aqui tratadas.

A sociedade embutida de seus valores e costumes, acaba por optar pelo tipo de Estado que anseia. E, eles, como representantes, atuam decidindo e fazendo gestão pública que recaem sobre os grupos sociais, os cidadãos e os agentes financeiros (MATIAS-PEREIRA/2007).

Segundo Matias-Pereira (2007, p. vii), a sociedade é diretamente responsável pela forma de atuação do Estado, tendo em vista que ela escolhe seus líderes governamentais e, conseqüentemente decide por uma forma de governar. A gestão pública escolhida, direta ou indiretamente, tem influência direta nos diversos segmentos sociais e econômicos.

Para Matias-Pereira (2007), esta gestão fará opções que poderão beneficiar a sociedade e fortalecer as instituições na qual estão inseridas. $O$ contrário, também é possível. As instituições podem ser enfraquecidas, podem apresentar prejuízos financeiros e operacionais, maculando a sua imagem institucional perante a população.

No Brasil, como no restante do mundo, os gestores públicos e privados têm procurado acompanhar as tendências administrativas em diversos setores. E o objetivo dos novos gestores, no tocante à economia e finanças, é seguir as legislações internacionais que regulam as atuações do homem com vistas a proteger patrimônios e interesses diferenciados.

Para Matias-Pereira (2007, p 41), um bom gestor público deve trabalhar embasado em quatro princípios: relações éticas; conformidade, em todas as suas dimensões; transparência; e prestação responsável de contas.

Todos os cidadãos anseiam por um governo transparente $\mathrm{e}$ responsável. E isto, em todas as extensões de atuação estatal. Bem sabemos que a atuação do estado não se resume à saúde, segurança e educação. $O$ governo atua fortemente na economia, regulando o mercado financeiro e as instituições que o compõem. 
De acordo com Matias-Pereira (2007, p. 5)

A administração pública, definida em termos amplos, abrange todas as operações que têm por propósito a realização ou o cumprimento dos desígnios públicos. Assim, a administração pública pode ser percebida como a estrutura do poder executivo, que tem a missão de coordenar e implementar as políticas públicas. Apresenta-se como um conjunto de atividades diretamente destinadas à execução concreta das tarefas consideradas de interesse público ou comuns numa coletividade ou numa organização estatal.

Neste contexto de atuação ampla do estado, destaca-se aqui a participação governamental no segmento bancário. Tal procedimento faz-se necessário com vistas à regulação das práticas desenvolvidas no mercado, bem como para preservar e fortalecer a economia nacional.

O mercado financeiro é muito dinâmico. As transações rápidas e a celeridade de alguns processos, como também os riscos aos quais o referido mercado fica exposto preocupam governos de todo o mundo.

Visando regular e proteger o mercado financeiro internacional, governantes de diversos países, há décadas, se reúnem para encontrar soluções, estabelecer regras, apresentar recomendações, reorientação estratégica e parâmetros operacionais de instituições financeiras. Um dos principais demonstrativos dessa intervenção, e considerado também o mais recente é o Acordo da Basiléia. < Disponível em: Iluniversidadecaixa.caixa. Acesso em 25/05/2010>.

Em 1988, representantes do G-10 ${ }^{1} \cdot$, se reuniram na cidade de Basiléia, na Suiça e promulgaram o Acordo de Capital da Basiléia. A intenção inicial foi criar um fórum de debates a respeito das diretrizes a serem seguidas

\footnotetext{
${ }^{1}$ G 10: grupo que surgiu em 1962, numa reunião convocada pelos EUA para aumentar os recursos disponíveis do FMI (Fundo Monetário Internacional), por meio do Acordo Geral de Empréstimos (GAB).É composto por onze países, fazem parte: Bélgica, Canadá, França, Alemanha, Itália, Japão, Holanda, Suécia, Suíça, Reino Unido e Estados Unidos. <disponível em:II universidadecaixa.caixa.br) $><$ Acesso em 25/04/2010 $>$.
} 
pelas instituições financeiras mundiais. Dentre elas destacamos a estabilidade do sistema bancário internacional. <Disponível em: lluniversidadecaixa.caixa>. $<$ Acesso em 25/04/2010 >.

Para Fajardo (2009), o Basiléia I foi um marco na regulação bancária, pois inicialmente sua aplicação era direcionada aos bancos internacionalmente ativos, com o tempo espraiou-se e passou a ser aplicado em todos os bancos e instituições financeiras, independentemente do tamanho e de figurarem ou não no âmbito internacional.

Para Fajardo, (2009, p.3), o mercado evoluiu, novas práticas surgiram e, conseqüentemente, falhas ou lacunas foram identificadas, tornando-se necessário a introdução de ajustes, principalmente depois que uma nova consciência aflorou sobre os riscos do mercado financeiro. Em 1996, - Acordo sofreu algumas alterações, passando a incluir, além do risco de crédito, o risco de mercado, ou seja, aquele decorrente de variações dos preços das ações, títulos, descasamento entre taxas de câmbios, etc

E, no ano de 2002, após a divulgação dos escândalos oriundos de fraudes contábeis em empresas norte-americanas, um novo acordo, conhecido como Basiléia II, foi aprovado pelo congresso dos Estados Unidos. Desta vez, diferentemente do anterior, o acordo apresentou-se mais consistente.

Conforme observação de Fajardo (2009, p.8), as principais mudanças foram o fim da padronização, adquirindo um viés mais flexível, com ênfase nos métodos de gerenciamento de risco dos bancos, na supervisão das autoridades bancárias e no fortalecimento da disciplina de mercado.

A nova estrutura tem a pretensão de alinhar a avaliação da adequação de capital aos principais elementos dos riscos bancários e fornecer incentivos aos bancos para aumentar suas capacidades de mensuração e administração dos riscos. <Disponível em: lopesfilhoeassociados.com.br> < Acesso em 30/04/2010>.

Desta forma, o Novo Acordo despertou maior sensibilidade aos riscos que os bancos assumem, implicando que o capital requerido varia de acordo com a maior ou menor propensão ao risco. O Basiléia II está calcado em três pilares: Capital Mínimo Requerido, Revisão no Processo de Supervisão e Disciplina de Mercado. 
Para Lastra (2000, p.22), o capital mínimo requerido é mantido em $8 \%$ para os ativos ponderados pelo risco. $\mathrm{Na}$ revisão do processo de supervisão bancária, os bancos serão avaliados como estão estimando a adequação de suas necessidades de capital em relação aos riscos assumidos. $\mathrm{O}$ segundo pilar é um incentivo à fiscalização. $\mathrm{E}$ o terceiro pilar estimula maior disciplina do mercado mediante o aumento da transparência dos bancos, a chamada transparência normativa.

Matias-Pereira (2006, p.1), faz a observação de que este acordo concorre com a Lei Sarbanes-Oxley $(\mathrm{SabOx})^{2}$. Tal lei não obteve a receptividade do Basiléia II, talvez pelos seus altos custos de implementação, segundo o autor.

Ressalta-se que, segundo Matias-Pereira (2006, p.2), as orientações do Acordo de Basiléia vêm sendo seguidas por bancos e instituições financeiras de diversos continentes. Atualmente, mais de cem instituições aderiram ao acordo. E, no Brasil, o mercado bancário tem seguido com propriedade as diretrizes estabelecidas.

No Brasil, o governo controla cinco bancos, dentre eles foi escolhido uma empresa pública para trata-se sobre a adaptação da operacionalização de seus produtos adequando-se aos princípios e normas da regulação prudencial, dentre eles especificamente o Acordo da Basiléia, o qual pela sua complexidade será tratado num capítulo à parte deste presente trabalho.

A empresa pesquisada, é uma empresa pública ${ }^{3}$, que desempenha ao mesmo tempo funções de banco social e comercial, conseguindo concorrer à altura com outros grandes bancos comerciais. Como parte de suas funções sociais opera programas de governos, tais como Bolsa Família, Seguro Desemprego, PIS, administra os recursos do FGTS, e os jogos de loterias. E ainda é o único banco brasileiro que trabalha com o sistema de penhor de jóias. Mas, a sua âncora maior é o financiamento habitacional.

\footnotetext{
${ }^{2}$ A Lei Sarbanes-Oxley foi assinada nos EUA no dia 30 de julho de 2002 é uma das mais rigorosas regulamentações sobre o estabelecimento de controles internos, a elaboração de relatórios fnanceiros e a divulgação de informações. <Disponível em: universidadecaixa.caixa.br > <Acesso em: 25/04/2010>.

${ }^{3}$ Empresa Pública é a entidade dotada de personalidade jurídica de direito privado, com patrimônio próprio e capital exclusivo da União. É criada por lei para a exploração de atividade econômica que o Governo seja levado a exercer por força de contingência ou de conveniência administrativa e pode revestir-se de qualquer das formas admitidas no Direito.< Disponível em: www.cgu.gov.br> < Acesso em 30/04/2010>.
} 
E, agora foi lançado um programa de governo denominado "Minha Casa, Minha Vida", operado pela empresa pesquisada, que visa suprir as deficiências habitacionais do nosso país. O governo federal está investindo $\mathrm{R} \$$ 34 milhões de reais para que muitos brasileiros consigam realizar o sonho da casa própria. < Disponível em: www.caixa.gov.br > < Acesso em 30/04/2010>.

O objetivo do Programa Minha Casa, Minha Vida é viabilizar a construção de 1 milhão de moradias para famílias com renda de até 10 salários mínimos, priorizando famílias com renda de até $R \$ 1.395,00$, mas que também abrange famílias com renda de até $R \$ 4.900,00$, em parceria com estados, municípios, empreendedores e movimentos sociais. <Disponível em: www.caixa.gov.br $><$ Acesso em 05/05/2010>.

Este programa ganhará um capítulo deste trabalho, pois apresenta significativa relevância como ato de gestão pública e elevada complexidade de informações técnicas.

Em relação aos serviços que o estado presta à sociedade, especificamente no mercado financeiro, no Brasil, ao contrário do restante do mundo, o sistema bancário está crescendo e apresentando lucros exorbitantes.

Portanto, além de prestar serviços à população, os bancos públicos brasileiros buscam cada vez mais os lucros incessantes. Para tal, arrecadam depósitos, pagam juros baixos e emprestam com taxas de juros elevadas.

Para Lastra (2000, p.70), um banco comercial é uma instituição basicamente alicerçada no recebimento de depósitos em espécie. Desempenhando também um papel de agente intermediador. Ou seja, recebe depósito de um cliente e empresta a outro mediante cobrança de juros.

No caso do sistema financeiro brasileiro, podemos dividi-lo em três fases, segundo Fajardo (2009, p. 06):

$1^{\text {a }}$ Fase: início do Plano Real, caracterizada pelos processos de transferência de controle acionário entre instituições financeiras privadas; modificações na legislação e na supervisão bancária e pela implementação do PROER (Medida provisória no 1.179/1995 - Programa de Estímulo à Reestruturação e ao Sistema Financeiro Nacional. Promovendo assim, o enxugamento do sistema financeiro mediante fusões entre bancos, aquisições, reorganizações societárias e reestruturação de instituições. 
$2^{\text {a }}$ Fase: iniciada em meados de 1996, caracterizada pelo ajuste de instituições e ingresso de bancos estrangeiros na economia brasileira.

$3^{\text {a }}$ Fase: em andamento. Caracterizada por reformas no modelo operacional dos bancos brasileiros.

Para Fajardo (2009, p.6), os bancos brasileiros estão liderando o processo de adequação das empresas brasileiras às novas exigências prudenciais, além de começado a utilizar ferramentas de controle interno para aprimorar a gestão. Visando diminuir riscos financeiros, operacionais e sistêmicos.

$\mathrm{Na}$ atualidade, destaca-se a importância do risco sistêmico, visto tratar-se da possibilidade de um choque localizado em algum ponto do sistema financeiro possa se transmitir ao sistema como um todo, e eventualmente, levar a um colapso da própria economia. Como acontecido recentemente nos Estados Unidos da América.

Conforme relatos de Fajardo (2009, p.3), em 2008, os Estados Unidos chegaram à beira de um grande desastre financeiro, originado na inadimplência de empréstimos habitacionais. Os bancos americanos, no afã de realizar negócios, emprestaram muito dinheiro para comprar casas, na forma de longo prazo, desburocratizando e facilitando o acesso às operações que, após algum tempo os americanos estavam tão endividados que não conseguiam manter em dia as prestações assumidas.

Para que os riscos sejam minimizados, faz-se necessário um bom planejamento estratégico, e nele, ocupando posição importante a regulação bancária, também conhecida como regulação prudencial ou supervisão bancária.

Planejamento estratégico é o planejamento de longo prazo, antecipando o futuro, e buscando colocar a instituição em lugar providencial no mercado no qual ela atua. É também um processo de mobilização de pessoas, empresa e governo, na construção do futuro. Como conseqüência do longo prazo, temos a necessidade de reajustes adequados à realidade vivenciada (MATIAS-PEREIRA, 2006).

Para Fajardo $(2009$, p.1), a regulação prudencial é uma forma de intervenção corretiva no sistema financeiro a fim de evitar a manifestação do contágio, ou seja, redução da exposição do sistema financeiro a riscos que 
possam se propagar por toda a economia. Tal regulação se dá de duas formas principais, com a criação de redes de segurança, para evitar que choques possam causar riscos sistêmicos e com a definição de regras de regulação e supervisão que reforcem a capacidade do sistema de evitar ou absorver choques.

Segundo D'Avila,(2002, p.18), com o advento da regulação bancária, as estratégias passaram a ser de tutelares para métodos nos quais o próprio banco são incentivados a mensurar seus riscos e melhorar seus sistemas de controle interno.

Para D’Avila (2002 p. 21), controle interno é um processo executado pelo conselho de administração, gerência e outras pessoas de uma organização, desenhado para fornecer segurança razoável sobre o alcance de objetivos nas seguintes categorias:

- eficácia e eficiência operacional;

- mensuração de desempenho e divulgação financeira;

- proteção de ativos;

- cumprimento de leis e regulamentações.

Conforme informações da página da Caixa Econômica Federal, na intranet, a estrutura de controles internos, quando implementada, é uma ferramenta que serve para assegurar se os executivos de uma organização se orientarão pela mesma direção para onde estão apontando os objetivos estratégicos definidos. <Disponível em: lluniversidadecaixa.caixa $>$ < Acesso em 30/04/2010>.

Isto posto, para D'Avila (2002, p. 22), o alcance dos objetivos de controle interno é fundamental para a salvaguarda dos ativos, alavancagem da lucratividade das operações e minimização do risco de descumprimento das normas que regulam a atividade. Para tanto, faz-se necessário uma constante reavaliação dos seus componentes.

Voltando à contextualização da empresa pesquisada, enquanto banco e sujeita à normas de regulação, ela também procurou adaptar-se ao marco regulatório ocorrido nos anos 90 .

Pelas razões expostas nos parágrafos anteriores, a empresa em questão deu início ao seu processo de mudança em 1998, resultando num plano de reestruturação no ano de 2001 , que incluiu um aporte de $R \$ 9,3$ 
bilhões pelo Tesouro Nacional. <Disponível em: Iluniversidadecaixa.caixa> < Acesso em 30/04/2010>.

Assim, reformulando a sua arquitetura organizacional, a empresa criou uma Superintendência de Retaguarda. E, a partir daí algumas atividades foram segregadas e desvinculadas das agências. Nascendo em cada unidade, uma espécie de "célula", desempenhando tarefas de conferência, conformidade e controle.

Os procedimentos de abertura de contas e concessão de empréstimos, por exemplo, são negociados na "linha de frente", que é a agência. Mas, a conferência de autenticidade de documentação, verificação da situação creditícia do cliente, comprovação de margem para pagamento de empréstimos e etc, são finalizados na retaguarda.

Quando existem inconformidades, ou seja, faltam documentos ou situação impeditiva de crédito, os empregados da retaguarda "marcam" a conta e "abortam" aquela negociação. Existe, portanto, uma segregação de funções e atividades, que visam assegurar todo o processo.

A partir desta limitação existem divergências quanto até que ponto esta regulação é benéfica aos negócios financeiros. Ou seja, ao mesmo tempo em que confere segurança, ela retarda o tempo para concretização efetiva das operações comerciais.

Atualmente existe um estudo, dentro da empresa, sobre uma possível reestruturação da área de retaguarda. Entretanto, até o presente momento nada foi definido, por isto tal fato poderá ser comentado no decorrer do desenvolvimento desta pesquisa. 


\subsection{O Comitê de Basiléia}

Com a globalização, o sistema financeiro se internacionalizou em um grau sem precedentes. A sofisticação das atividades bancárias, a reboque da globalização das economias trouxe dinamicidade ao setor financeiro, expandindo a sua exposição a eventos que podem interferir nos resultados desejados.

O fim do Sistema Monetário Internacional, baseado em taxas de câmbio fixas, trouxe momentos de intensa volatilidade ao mercado financeiro mundial. A liberação de taxas agravou o risco do sistema e exigiu a adoção de medidas que minimizassem o fato.

Visando a minimização da gravidade dos riscos, os responsáveis pela supervisão bancária nos países do G-10 criaram o Comitê de Regulamentação Bancária e Práticas de Supervisão, com sede no Banco de Compensações Internacionais - BIS, em Basiléia, na Suiça.

Esse Comitê é constituído por representantes dos bancos centrais e por autoridades com responsabilidade formal sobre a supervisão bancária dos países-membros do G-10, sendo neles discutidas questões relacionadas à melhoria da qualidade da supervisão bancária e fortalecimento da segurança do sistema bancário internacional.

\subsubsection{O Acordo da Basiléia}

Atuando desde 1975, o Comitê de Basiléia, como ficou conhecido, criou uma série de estudos que culminaram, em 1988, num documento denominado Acordo de Capital Mínimo ou, simplesmente, Acordo de Basiléia ou Basiléia I. Este acordo basicamente dispunha sobre a necessidade do banco manter um montante mínimo de capital necessário para suportar o risco de crédito assumido.

Em termos gerais, o cálculo do Capital Mínimo considerava o valor de risco de crédito associado a cada linha de negócio firmada com o governo, com outras instituições bancárias (interbancário), com o varejo e com o mercado corporativo. 
Essas linhas, citadas no documento como as "contrapartes" das negociações, tinham que ser classificadas conforme o risco que representavam e esse risco era calculado pela aplicação dos pesos/ponderações que variavam entre $0 \%$ a $300 \%$. Aplicados os pesos, os ativos passavam a ser denominados ativos ponderados, cujo somatório indicava a base de cálculo para encontrar o valor em risco que deveria ser coberto por certa quantidade de capital.

No mesmo documento, ainda para calcular o valor de capital mínimo, o Acordo de Basiléia recomendava que sobre o ativo ponderado a instituição aplicasse o percentual de $8 \%$, o que forneceria o montante ideal de capital para suportar as opções de aplicações realizadas pelo banco. No Brasil, - Banco Central foi um pouco mais conservador e substituiu o percentual recomendado para o valor de $11 \%$.

Com o passar do tempo, a fórmula inicial que considerava apenas o ativo ponderado e um percentual definido pelos supervisores passou a apresentar novos requerimentos, contemplando parcelas de risco de crédito que envolviam operações de swap, risco de variação cambial e taxa de juros. Nessa época, no Brasil, esses três últimos valores eram obtidos com a consulta às rubricas contábeis específicas que registravam essas informações, sem impor grandes dificuldades ao banco para calcular o valor do capital mínimo.

Após a publicação do Acordo de Basiléia, os trabalhos no BIS continuaram na forma de pesquisas realizadas em várias instituições pelo mundo, ao mesmo tempo em que continuavam a discutir novas situações, e a gerar novas recomendações que foram sendo incorporadas ao conjunto de material produzido no âmbito do Comitê.

Nove anos depois da publicação do primeiro acordo, em 1997, o Comitê da Basiléia emitiu um documento contendo os 25 princípios que norteiam a supervisão bancária eficaz; desde então, os bancos centrais, entre eles o BACEN, têm procurado transformar em normas para o sistema financeiro nacional cada um dos princípios divulgados, os quais apresentamos resumidamente:

1) Pré-condições para uma supervisão efetiva (organização, independência, poder, transparência e cooperação);

2) Atividades permitidas;

3) Critérios para a concessão de licenças; 
4) Transferência de controle acionário;

5) Grandes aquisições/investimentos;

6) Capital adequado;

7) Processo de gerenciamento de riscos;

8) Risco de crédito;

9) Problemas de ativos, provisões e reservas;

10) Limites de exposição;

11) Exposição para partes relacionadas;

12) Risco soberano e de transferências;

13) Risco de mercado;

14) Risco de liquidez;

15) Risco operacional;

16) Risco de taxa de juros;

17) Controle interno;

18) Práticas de conheça o cliente;

19) Abordagem de supervisão;

20) Técnicas de supervisão;

21) Definir meios para capturar, rever e analisar relatórios e estatísticas sobre as instituições financeiras, na forma individual ou consolidada;

22) Responsabilidade e transparência;

23) Ações corretivas tempestivas do supervisor;

24) Supervisão consolidada;

25) Compartilhamento de informações entre supervisores.

Se desejarmos conhecer a lógica dos 25 princípios de forma agrupada, é possível analisá-los a partir de alguns poucos conjuntos que representam os macro-objetivos do Comitê, conforme abaixo:

a) Pré-condições para uma supervisão efetiva (princípio 1);

b) Definições claras sobre a estrutura, as atividades permitidas às instituições financeiras e sobre a atuação dos supervisores (princípios 2 a 5);

c) Requerimentos e normas prudenciais (princípios 6 a 16);

d) Padrão para métodos de supervisão bancária contínua (princípios 7 a 21 ); 
e) Requisitos para informação (princípio 22);

f) Poderes formais dos supervisores (princípio 23);

g) Supervisão além do país (princípios 24 e 25). 


\subsection{Programa Minha Casa, Minha Vida}

O Programa Minha Casa, Minha Vida - PMCMV, lançado pelo Governo Federal e, executado inicialmente, pela CAIXA, constitui-se de um conjunto de medidas do Governo Federal dispostas na Lei 11.977/2009.

A Lei 11.977/2009, 07 de julho de 2009, dispõe sobre o PMCMV, regularização fundiária de assentamentos localizados em áreas urbanas, e dá outras providências. Determina também que o PMCMV tem como finalidade criar mecanismos de incentivo à produção e à aquisição de novas unidades habitacionais pelas famílias com renda de até dez salários mínimos.

Destaca-se o emprego da palavra "novas" que implica dizer que somente imóveis novos serão financiados dentro do PMCMV. Essa exigência evidencia que o objetivo do governo é incentivar a construção de novas unidades residenciais visando à redução do déficit habitacional e à criação de novos empregos.

Em resumo, o PMCMV visa atender duas políticas:

-Política Anticíclica: aumentar o investimento na construção civil e a geração de emprego.

-Política Social: aumentar o acesso à casa própria, minimizando o déficit habitacional.

O PMCMV compreende:

-O Programa Nacional de Habitação Urbana - PNHU e a autorização para a União participar do Fundo Garantidor da Habitação Popular - FGHab.

-O Programa Nacional de Habitação Rural - PNHR

-A autorização para a União tranferir recursos ao Fundo de Arrendamento Residencial - FAR e ao Fundo de Desenvolvimento Social FDS, visando financiar unidades habitacionais com recursos desses fundos.

O programa Minha Casa, Minha Vida tem linhas de financiamentos diferentes para cada tipo de família: 


\section{Para quem ganha até três salários mínimos}

A maior parte dos recursos do programa Minha Casa, Minha Vida vai para famílias que ganham até $R \$ 1.395,00$ por mês, faixa da população que tem menos oportunidades de conseguir um financiamento para a casa própria.

O Governo vai investir até R 16 bilhões para baratear a prestação e permitir que 400 mil moradias sejam construídas. O valor mínimo das parcelas é de $R \$ 50,00$ para construção ou compra de casas novas ou usadas.

Vantagens Oferecidas:

- O comprador não paga seguro do financiamento habitacional, que é obrigatório e aumenta o preço das parcelas.

- Custo com cartório para registrar o imóvel também é zero.

- A prestação será de no mínimo $R \$ 50,00$ e não poderá comprometer mais de $10 \%$ da renda da família por 10 anos. Por exemplo: Se o orçamento familiar mensal é de $\mathrm{R} \$ 1.000,00$, o comprador terá prestações iniciais de no máximo $R \$ 100,00$.

- A compra da casa pode ser feita sem entrada, mas recursos do FGTS podem ser usados no financiamento.

- A Caixa Econômica Federal é responsável pela análise dos projetos.

- Famílias com portadores de deficiência ou idosos têm prioridade.

- A liberação do financiamento é mais ágil se o imóvel for registrado em nome da mulher.

\section{Para quem ganha de três a seis salários mínimos}

Famílias com renda de até $\mathrm{R} \$ 2.790,00$ podem dispor de mais recursos do FGTS para a compra da casa própria no valor máximo de $\mathrm{R} \$ 130$ mil, com taxas de juros reduzidas, de no máximo $6 \%$ ao ano.

Para essa faixa de renda, o governo criou um fundo garantidor para casos de problemas com o pagamento das parcelas e reduziu o valor do seguro do financiamento, além cortar em $90 \%$ os custos de cartório para registrar o imóvel. A família não poderá comprometer mais de $20 \%$ do orçamento mensal com o negócio. 
Vantagens Oferecidas:

-O Governo Federal investirá R \$2,5 bilhões; dinheiro do FGTS foi ampliado em $\mathrm{R} \$ 7,5$ bilhões. Os valores funcionam como subsídio no pagamento da entrada do financiamento, podendo variar de $R \$ 13$ mil a $R \$ 23$ mil.

- Além da redução do preço do seguro habitacional, o comprador conta com um fundo garantidor, instrumento para refinanciar eventuais dívidas do negócio em caso de perda da renda. Esse fundo renegocia o pagamento de até 36 prestações.

- Taxa de juros entre $5 \%$ e $6 \%$.

\section{Quem ganha de seis a dez salários mínimos}

Para as famílias nesta faixa de renda (até $R \$ 4.650,00$ ), o programa Minha Casa, Minha Vida garante redução dos custos do seguro do financiamento e acesso ao fundo garantidor, instrumento que garante a renegociação de dívidas.

Vantagens Oferecidas:

- Redução de $80 \%$ dos custos com cartório para registro de imóveis.

- Refinanciamento de parte das prestações em caso de perda da renda, por meio do fundo garantidor. Prestações garantidas: entre 12 e 24 .

- Uso dos recursos do FGTS do comprador para pagamento da entrada do financiamento.

- Barateamento do preço do seguro de financiamento habitacional.

\section{Déficit habitacional brasileiro}

Além de estimular a economia e reduzir os efeitos da crise financeira internacional, que estourou nos Estados Unidos em 2008, o programa Minha Casa, Minha Vida pretende reduzir o déficit habitacional brasileiro ao construir um milhão de casas e apartamentos.

O Governo Federal calcula que é necessário construir mais de 7 milhões de domicílios para acabar com o problema da falta de moradia no país. 
De acordo com a estratégia do programa, os mais de $R \$ 30$ bilhões previstos em investimentos serão distribuídos conforme a renda e a região.

\section{MÉTODOS E TÉCNICAS DE PESQUISA}

Nesse presente trabalho, com vistas à identificação da aplicabilidade operacional da análise dos dossiês do Programa Minha Casa Minha Vida, bem como a conseqüente liberação de alçadas, na Retaguarda do banco pesquisado, será utilizado o método de pesquisa quantitativa.

Para conferência dos dados obtidos será efetuada uma análise documental de todos os dados obtidos durante a nossa pesquisa.

\subsection{População e Amostra}

Tendo em vista a grande quantidade de retaguardas existentes neste banco, que somam o total de 2.022 unidades, envolvendo cerca de 70.000 empregados, com extensões localizadas em todo o território brasileiro, e a impossibilidade de abarcamos todas as pessoas envolvidas neste processo, optamos por selecionar uma amostra aleatória.

Neste caso, a amostra estudada será selecionada entre os empregados do Distrito Federal, lotados nas retaguardas e nas agências da empresa pesquisada. Participando desta etapa 10 empregados das retaguardas e 10 das agências.

\subsection{Instrumentos}

Como instrumentos de coleta de dados serão utilizados questionários estruturados, elaborados a partir de perguntas embasadas no trâmite operacional da liberação de um financiamento do PMCMV.

Para melhor quantificar, as perguntas serão fechadas, induzindo a respostas também fechadas mensuráveis de 0 a 5 . 


\subsection{Coleta de Dados}

Os dados foram coletados mediante o envio de mensagens eletrônicas contendo uma breve explicação sobre o assunto, e com o questionário em anexo.

\subsection{Análise de Dados}

Os dados obtidos serão analisados mediante um estudo documental das informações recebidas, seguindo um critério de pontuação crescente para cada item respondido. 


\section{REGISTRO DOS RESULTADOS E DISCUSSÃO}

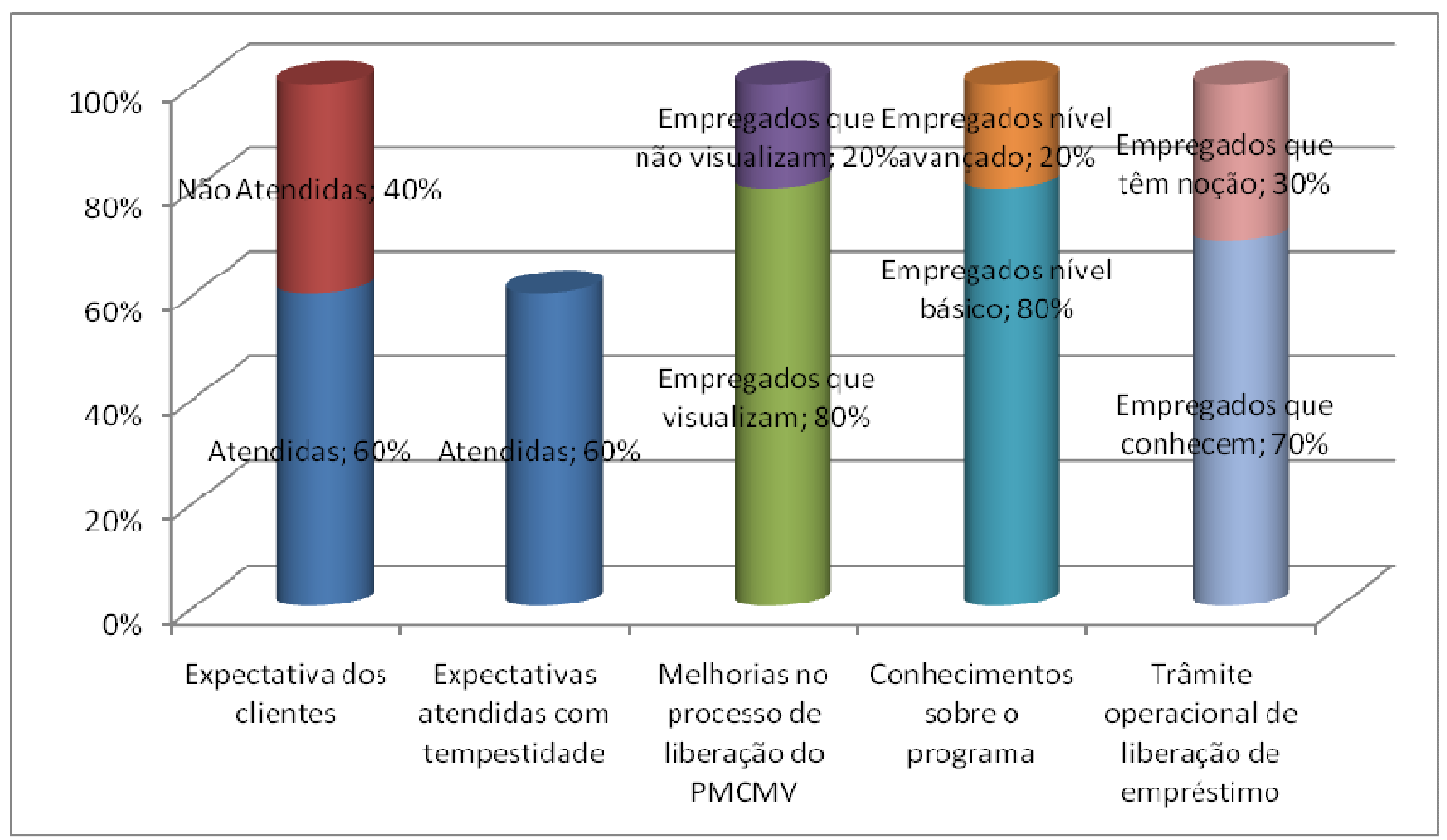

O questionário foi aplicado a 20 empregados, sendo 10 de agências e 10 empregados lotados na retaguarda bancária.

Os questionários foram enviados mediante correio eletrônico, contendo uma breve explicação sobre do que se tratava. Estipulou-se o prazo de 03 dias para devolução do questionário com as devidas respostas.

Após esse procedimento pode-se observar as seguintes situações:

> Dos 20 empregados, somente 12 devolveram no prazo combinado;

> 6 empregados enviaram um dia depois;

$>2$ empregados tiveram que ser cobrados por telefone e mensagens.

Já de posse dos questionários respondidos, deu-se início à tabulação das respostas obtidas.

Os resultados foram os seguintes:

> A maioria absoluta, ou seja, 100\% dos empregados afirmaram não dispor de tempo suficiente para dar vazão às demandas recebidas;

$>$ Quanto às expectativas dos clientes, 12 consideraram que estão sendo atendidas, e 08 consideraram que não estão sendo atendidas; 
> $80 \%$ dos empregados conseguem visualizar melhorias no processo de liberação do PMCMV, mediante a diminuição das exigências burocráticas e a melhoria dos sistemas corporativos;

> $60 \%$ dos empregados consideram que a retaguarda tem atendido às expectativas com tempestividade;

> $80 \%$ dos empregados demonstraram conhecimentos básicos sobre 0 programa, e somente $20 \%$ conhecem com mais profundidade;

> $100 \%$ dos empregados afirmaram que os clientes têm a expectativa de serem atendidos em no máximo 01 mês;

> 70\% conhecem o trâmite operacional da liberação de um empréstimo, o restante apresenta somente uma noção;

> Na opinião da maioria, ou seja, $100 \%$ dos empregados, acreditam que a análise e a liberação deveriam ser feitos na retaguarda bancária para que eles pudessem ganhar tempo fazendo negócios;

> $100 \%$ dos empregados citaram como vantagem da segregação de tarefas, o fato de minimizar prejuízos e fraudes financeiras;

$>100 \%$ dos empregados participantes da entrevista, visualizam a retaguarda bancária como uma unidade de conformidade e controle das operações.

> Somente 03 empregados fizerem sugestões e observações. Destacando-se a sugestão de que o questionário fosse aplicado a um número maior de pessoas.

Assim, após a coleta e análise de dados, pode-se inferir que o papel da retaguarda sugere um maior controle/acompanhamentos das operações efetuadas nas agências, trazendo conseqüentemente, mais segurança aos empregados e à empresa.

Quanto à aplicabilidade operacional do PMCMV dentro das retaguardas bancárias, pode-se afirmar que tal sistemática é bem vista pelos empregados. Principalmente pelo fato de que desta maneira os empregados das agências terão mais tempo disponível para desenvolver outras atividades. 


\section{CONCLUSÃO}

Em seguida à análise dos dados obtidos nos questionários aplicados, foi possível chegar-se a algumas conclusões.

Em primeiro lugar, ressalta-se a importância do alcance dos objetivos desta pesquisa.

Em decorrência do êxito no objetivo proposto no escopo desse projeto, corrobora-se o fato de que a retaguarda desempenha um importante papel dentro da instituição pesquisada. Inclusive, proporcionando uma imagem de segurança a todos os empregados.

Também pode-se afirmar, com base nos dados obtidos, que a aplicabilidade operacional do PMCMV inserido na retaguarda bancária é uma sistemática bastante viável e bem aceita pelo corpo funcional.

Portanto, ressalta-se que esta pesquisa contribuiu para o aprimoramento dos processos da empresa em questão. Sendo bastante salutar a divulgação da mesma no âmbito corporativo.

Para finalizar, recomenda-se a revisão do fluxo operacional dos documentos, visto que há uma redundância de solicitação dos mesmos documentos com a mesma finalidade. Por exemplo: comprovação de residência necessita ser feita diversas vezes.

A utilização dos sistemas corporativos também precisa ser revista, pois existe dispêndio de tempo na inserção dos mesmos dados em diversos sistemas. Por exemplo: atualmente insere-se dados relativos à comprovação de renda e residência, em pelo menos 03 (três) sistemas corporativos.

É recomendável que, os dados do cliente, obtidos no processo de abertura de contas, sejam utilizados na concessão do empréstimo. Fazendo-se necessário somente a atualização cadastral.

Desta forma os processos operacionais serão minimizados, reduzindo fluxos e tarefas, e atingindo o objetivo da organização de atendimento aos clientes dentro de expectativas mais próximas do esperado. 


\section{REFERÊNCIAS}

D’AVILA, Marcos Zahler; OLIVEIRA, Marcelo Aparecido Martins . Conceitos e Técnicas de Controles Internos de Organizações. São Paulo: Nobel, 2002.

DIAS, Leila Christina;LENZI, Maria Helena Reorganização espacial de redes bancárias no Brasil: processos adaptativos e inovadores. Cad. $\mathrm{CRH}, \mathrm{Abr}$ 2009, vol.22, no.55, p.97-117. ISSN 0103-4979.

FAJARDO, Jeison de Melo. A Regulação prudencial e os princípios para melhoria das operações bancárias nacionais e como o Brasil se preparou para a pior crise econômica mundial desde 1929. Rev. Contábil e Empresarial Fiscolegis (online). 2010.

FONTES FILHO, Joaquim Rubens;PICOLIN, Lidice Meireles. Governança corporativa em empresas estatais: avanços, propostas e limitações. Rev. Adm. Pública [online]. 2008, vol.42, n.6, pp. 1163-1188. ISSN 0034-7612.

LASTRA, Rosa Maria. Banco Central e Regulamentação Bancária. Belo Horizonte: Del Rey, 2000.

MATIAS-PEREIRA, José. Administração Pública Comparada: uma avaliação das reformas administrativas do Brasil, EUA e União Européia. Ver. Administração Pública. 2008, vol. 42, pp. 61-82. ISSN 0034-7612.

MATIAS-PEREIRA, José. Os reflexos do Acordo de Basiléia II no Sistema Financeiro Mundial. Rev. Contábil e Empresarial Fiscolegis (online). 2010.

MATIAS-PEREIRA, José. Manual de Gestão Pública Contemporânea. São Paulo: Atlas, 2007.

<www.caixa.gov.br>

<lluniversidadecaixa.caixa>

$<\underline{w w w \cdot b c b . g o v \cdot b r}>$ 
www.planalto.gov.br 


\section{ANEXOS}

\section{Anexo I - Questionário de Pesquisa}

Questionário destinado a levantamento de dados para embasamento de Trabalho de Conclusão de Curso, na graduação de Administração a Distância, Unb.

Refere-se à efetividade operacional do Programa Minha Casa, Minha Vida, na retaguarda bancária.

Ressaltamos que todas as informações e dados aqui obtidos serão confidenciais.

1) Você dispõe de tempo suficiente para atender o cliente e operacionalizar as suas demandas durante a sua jornada de trabalho? (sem horasextras)

a) ( ) Não Totalmente

b) ( ) Não. Parcialmente

c) ( ) Indiferente

d) ( ) Sim. Parcialmente

e) ( ) Sim. Totalmente

2) Você considera que as expectativas do cliente estão sendo atendidas?

a) ( ) Não Totalmente

b) ( ) Não. Parcialmente

c) ( ) Indiferente

d) ( ) Sim. Parcialmente

e) ( ) Sim. Totalmente 
3) Você consegue visualizar melhorias no processo de liberação do PMCMV?
a) ( ) Não Totalmente
b) ( ) Não. Parcialmente
c) ( ) Indiferente
d) ( ) Sim. Parcialmente
e) ( ) Sim. Totalmente

4) A retaguarda do banco no qual você trabalha tem atendido tempestivamente suas demandas?
a) ( ) Não Totalmente
b) ( ) Não. Parcialmente
c) ( ) Indiferente
d) ( ) Sim. Parcialmente
e) ( ) Sim. Totalmente

5) O que você sabe a respeito do Programa Minha Casa, Minha Vida?

6) Qual a expectativa, em média, que o cliente do PMCMV, tem a respeito da liberação do financiamento pretendido?

7) Qual o trâmite da proposta do cliente desde o momento em que ele procura o banco para obter um financiamento do PMCMV até a liberação do empréstimo?

8) Na sua opinião, a análise e liberação do PMCMV deveria ser feita na agência ou na retaguarda? Por quê?

9) Quais as vantagens e desvantagens da segregação de tarefas no PMCMV? 
10)Qual a sua visão sobre o papel de uma retaguarda bancária dentro de um banco público?

11)Espaço disponibilizado para sugestões e observações. 


\section{Anexo II - Princípios do Acordo da Basiléia}

Princípio 1 - Objetivos, independência, poderes, transparência e cooperação: Um sistema efetivo de supervisão bancária terá as responsabilidades e os objetivos de cada autoridade envolvida na supervisão de organizações bancárias claramente definidas. Cada uma dessas autoridades deve possuir independência operacional, processos transparentes, governança sólida e recursos adequados, e deve ser responsabilizada pelo desempenho de suas atribuições. Uma estrutura legal apropriada à supervisão bancária também é necessária, incluindo dispositivos relacionados às autorizações para o estabelecimento das organizações bancárias e à sua supervisão contínua; poderes voltados para a verificação de conformidade com as leis e com as preocupações de segurança e solidez; e proteção legal para os supervisores. Devem existir mecanismos para a troca de informações entre supervisores e proteção da confidencialidade de tais informações.

Princípio 2 - Atividades permitidas: As atividades que serão permitidas às instituições que são autorizadas a funcionar como bancos e estão sujeitas à supervisão precisam ser claramente definidas e o uso da palavra "banco" em nomes deve ser controlado da melhor forma possível.

Princípio 3 - Critério para Autorização de Funcionamento: A autoridade que concede permissão de funcionamento deve ter o poder de determinar critérios e rejeitar requerimentos de estabelecimentos que não atinjam o padrão determinado. O processo de autorização deve consistir, no mínimo, de uma avaliação da estrutura de propriedade e da governança do banco e do grupo ao qual pertence, incluindo a adequação e as propriedades dos membros do Conselho e da alta administração, seus planos estratégicos e operacionais, controles internos e gerenciamento de riscos, e sua condição financeira projetada, incluindo a sua estrutura de capital. Se o proprietário ou a organização controladora proponente for um banco estrangeiro, deve ser obtido o consentimento prévio do supervisor do país de origem antes que a autorização de funcionamento seja concedida. 
Princípio 4 - Transferência Significativa de Propriedade: O supervisor tem o poder de revisar e rejeitar qualquer proposta de transferência significativa de propriedade ou controle de interesses mantidos direta ou indiretamente pelos bancos para terceiros.

Princípio 5 - Grandes Aquisições: O supervisor tem o poder de revisar, usando critérios pré-estabelecidos, grandes aquisições ou investimentos que um banco pretenda fazer, incluindo o estabelecimento de operações no exterior, assegurando que filiais ou estruturas corporativas não exponham o banco a riscos indevidos ou dificultem uma supervisão efetiva.

Princípio 6 - Adequação de Capital: Os supervisores devem estabelecer requerimentos mínimos prudentes e apropriados de adequação de capital aos bancos, que reflitam os riscos aos quais o banco está submetido, e devem definir os componentes de capital, tendo em mente sua habilidade de absorver perdas. Ao menos para bancos internacionalmente ativos, esses requerimentos não devem ser inferiores aos estabelecidos no requerimento aplicável do Acordo da Basiléia.

Princípio 7 - Processo de gerenciamento de riscos: Os supervisores precisam se assegurar de que os bancos e grupos bancários adotam um processo abrangente de gerenciamento de riscos (incluindo participação do Conselho e da alta administração) para identificar, avaliar, monitorar e controlar ou mitigar todos os riscos materiais e para verificar a adequação de seu capital frente ao seu perfil de risco. Esses processos devem ser proporcionais ao porte e à complexidade da instituição.

Princípio 8 - Risco de Crédito: Os supervisores precisam se assegurar de que os bancos possuem processos de gerenciamento de risco de crédito que levam em consideração o perfil de risco da instituição, com políticas prudentes e procedimentos para identificar, medir, monitorar e controlar o risco de crédito (incluindo o risco de contraparte). Isso inclui a concessão de empréstimos e a 
realização de investimentos, a avaliação da qualidade de tais empréstimos e investimentos, e o gerenciamento contínuo das carteiras de empréstimos e de investimentos.

Princípio 9 - Ativos problemáticos, provisões e reservas: Os supervisores devem se assegurar de que os bancos estabelecem e seguem políticas e processos adequados para gerenciar ativos problemáticos e para avaliar a adequação de provisões e reservas.

Princípio 10 - Limites para grandes exposições: Os supervisores devem se assegurar de que os bancos adotam políticas e processos que permitam aos gestores a identificação e o gerenciamento de concentrações dentro da carteira, e os supervisores devem estabelecer limites prudentes para restringir exposições bancárias a contrapartes isoladas ou a grupos de contrapartes conectadas.

Princípio 11 - Exposições a partes relacionadas: Com o objetivo de prevenir abusos originados das exposições (tanto nas contas patrimoniais como nas de compensação) a partes relacionadas e para tratar o conflito de interesses, os supervisores devem impor o requerimento de que as exposições a companhias e indivíduos relacionados sejam limitadas; que essas exposições sejam efetivamente monitoradas; que medidas apropriadas sejam tomadas para controlar ou mitigar os riscos; e que a baixa contábil dessas exposições seja feita de acordo com políticas e processos padronizados.

Princípio 12- Riscos país e de transferência: Os supervisores precisam se assegurar de que os bancos possuem políticas e processos adequados para identificar, medir, monitorar e controlar o risco país e o risco de transferência em seus empréstimos internacionais e atividades de investimento, e para manter provisões e reservas adequadas para se resguardarem desses riscos.

Princípio 13 - Riscos de Mercado: Os supervisores precisam se assegurar de que os bancos possuem políticas e processos adequados para identificar, medir, monitorar e controlar de forma precisa os riscos de mercado; os supervisores devem possuir poderes para impor limites específicos e/ou impor 
um requerimento de capital específico sobre exposições a risco de mercado, se for necessário.

Princípio 14 - Risco de Liquidez: Os supervisores devem se assegurar de que os bancos adotam uma estratégia de gerenciamento de liquidez que leva em conta o perfil de risco da instituição, com políticas e processos prudentes para identificar, medir, monitorar e controlar o risco de liquidez, e para gerenciar a liquidez diariamente. Os supervisores devem exigir que os bancos possuam planos de contingência para resolver problemas de liquidez.

Princípio 15 - Risco operacional: Os supervisores devem se assegurar de que os bancos adotam políticas e processos de gerenciamento para identificar, avaliar, monitorar e controlar/mitigar o risco operacional. Essas políticas e processos devem ser compatíveis com o porte e a complexidade do banco.

Princípio 16 - Risco de taxa de juros no banking book: Os supervisores devem se assegurar de que os bancos adotam sistemas efetivos para identificar, medir, monitorar e controlar o risco de taxa de juros no banking book, incluindo uma estratégia bem definida que tenha sido aprovada pelo Conselho e implementada pela alta administração; esses controles devem estar de acordo com o tamanho e a complexidade de tal risco.

Princípio 17 - Controles internos e auditoria: Os supervisores devem se assegurar de que os bancos adotam controles internos adequados ao porte e complexidade de seus negócios. Isso deve incluir regras claras para delegação de autoridade e responsabilidade; separação das funções que envolvem decisões para a assunção de compromissos pelo banco, que dispõem de seus fundos, e que contabilizam seus ativos e passivos; reconciliação desses processos; proteção dos ativos do banco; e funções de auditoria interna independente e de verificação de conformidade apropriadas para testar a aderência a esses controles bem como a leis e regulamentos aplicáveis.

Princípio 18 -Integridade do setor bancário: Os supervisores devem se assegurar de que os bancos adotam políticas e processos adequados, 
incluindo regras rígidas do tipo "conheça seu cliente", que promovem altos padrões éticos e profissionais no setor financeiro e evitam que o banco seja usado, intencionalmente ou não, para atividades criminosas.

Princípio 19 - Abordagem do supervisor: Um sistema de supervisão bancária efetivo requer que os supervisores desenvolvam e mantenham uma compreensão completa das operações dos bancos individuais e das organizações bancárias, e também do sistema bancário como um todo, concentrando-se em segurança e solidez, e na estabilidade do sistema bancário.

Princípio 20 - Técnicas de Supervisão: Um sistema de supervisão bancária efetivo deve consistir de supervisão direta e indireta, além de contatos regulares com a administração do banco.

Princípio 21 - Relatórios para a supervisão: Os supervisores devem possuir meios de coletar, rever e analisar relatórios prudenciais e informações estatísticas dos bancos tanto em bases individuais como consolidadas, e meios de realizar uma verificação independente desses relatórios, através de seus exames diretos (na instituição) ou do uso de especialistas externos.

Princípio 22 - Contabilidade e divulgação: Os supervisores devem se assegurar de que cada banco mantém registros adequados realizados de acordo com políticas e práticas contábeis amplamente aceitas internacionalmente, e publique regularmente informações que reflitam fielmente sua condição financeira e sua rentabilidade.

Princípio 23 - Ações corretivas e os poderes dos supervisores: Os supervisores devem ter ao seu dispor uma gama adequada de ferramentas de supervisão para demandar ações corretivas em tempo hábil. Isto inclui o poder de, quando apropriado, caçar a licença de funcionamento do banco, ou recomendar a sua revogação. 
Princípio 24 - Supervisão consolidada: Um elemento essencial em supervisão bancária é a supervisão consolidada do grupo bancário, monitorando adequadamente e, quando apropriado, aplicando normas prudenciais a todos os tipos de negócios conduzidos mundialmente pelo grupo.

Princípio 25 - Relações entre supervisores domésticos e do exterior - A supervisão consolidada além das fronteiras do país exige cooperação e troca de informações entre os supervisores domésticos e os vários outros supervisores envolvidos, principalmente os supervisores bancários do país receptor. Os supervisores bancários devem requerer que as operações locais de bancos estrangeiros sejam conduzidas nos mesmos padrões requeridos para as instituições domésticas.

Os Princípios Fundamentais são neutros com relação a diferentes estilos de supervisão, desde que os principais objetivos sejam atingidos. Os Princípios não foram concebidos para cobrir todas as necessidades e circunstâncias de todos os sistemas bancários. Em vez disso, circunstâncias específicas de cada país serão consideradas de forma mais apropriada no contexto de avaliações do sistema e no diálogo entre avaliadores e autoridades do país.

Autoridades nacionais devem aplicar os Princípios na supervisão de todas as organizações bancárias sob sua jurisdição. Países individuais, em particular aqueles com mercados e instituições avançadas, podem ampliar os Princípios para atingir melhores práticas de supervisão.

Um alto grau de conformidade com os Princípios deve promover a estabilidade financeira de uma forma geral; no entanto, não vai garanti-la, nem vai prevenir a falência de bancos individuais. A supervisão bancária não pode, e não deve, fornecer a garantia de que os bancos não falirão. Em uma economia de mercado, falências são parte do risco a correr.

O Comitê mantém-se pronto para encorajar o trabalho em nível nacional para implementar os Princípios junto com outros órgãos supervisores e partes interessadas. O Comitê convida as instituições financeiras internacionais e agências doadoras a usar os Princípios quando prestarem assistência a países individuais para fortalecer os seus sistemas de supervisão. O Comitê 
continuará a colaborar estreitamente com o FMI e o Banco Mundial no monitoramento da implementação dos padrões prudenciais do Comitê. O Comitê compromete-se também a reforçar sua interação com supervisores dos países não pertencentes ao G-10. <Disponível em: www.bcb.gov.br > < Acesso em 15/10/2010>. 